This item was submitted to Loughborough's Research Repository by the author.

Items in Figshare are protected by copyright, with all rights reserved, unless otherwise indicated.

\title{
Bursting the bubble: Spatialising safety for privileged migrant women in Singapore
}

\section{PLEASE CITE THE PUBLISHED VERSION}

https://doi.org/10.1111/anti.12433

\section{PUBLISHER}

(c) 2018 The Author. (c) Antipode Foundation Ltd. Published by Wiley

\section{VERSION}

AM (Accepted Manuscript)

\section{PUBLISHER STATEMENT}

This is the peer reviewed version of the following article: CRANSTON, S. and LLOYD, J., 2018. Bursting the bubble: Spatialising safety for privileged migrant women in Singapore. Antipode, 51 (2), pp.478-496, which has been published in final form at https://doi.org/10.1111/anti.12433. This article may be used for non-commercial purposes in accordance with Wiley Terms and Conditions for Use of Self-Archived Versions.

\section{LICENCE}

CC BY-NC-ND 4.0

\section{REPOSITORY RECORD}

Cranston, Sophie, and Jenny Lloyd. 2018. "Bursting the Bubble: Spatialising Safety for Privileged Migrant Women in Singapore". figshare. https://hdl.handle.net/2134/34380. 


\section{Bursting the Bubble: Spatialising safety for privileged migrant women in Singapore}

This paper develops geographical work that is attentive to, and critical of, how safety is lived and narrated. In contrast to previous work on safety that focuses on fear, the paper looks at safety as something more than aspiration for women. To do so, the paper utilises the metaphor of the 'expatriate bubble' to explore how safety is constructed and experienced by privileged migrants within Singapore. Utilising research from two projects, we argue that we need to think about how gender and Othering intersect to construct safety. In doing so, we think about how we can use conceptualisations of privileged migrants to research how safety can be understood and therefore practised more widely.

\section{Introduction}

We live in a time when safety is never far from mind, be it: health and safety, online safety or heightened security. Yet, so little is known about what it is to feel safe. And while terrorist incidents may have placed safety on global agendas, for some groups - often women - the pursuit of safety, personal safety, is nothing new. With very few exceptions, in thinking about safety, the focus of studies in geography has often been on its opposite: fear. Research into fear has highlighted how fear of crime shapes, and is shaped by, people's use of space and the intersections of different identity markers such as race, class, age and gender (Pain 2001). In an age of increased surveillance, mistrust of 'others' and heightened global anxiety over the threat of terrorism (Philo 2012), discourses of fear have significant consequences in shaping domestic and foreign policy, with wide-reaching implications to people’s everyday experiences. While safety falls within this work, it remains elusive, an ambition that is not to be realised. Fear is the focal point of analysis, where safety is conceptualised only as the underlying aspiration. This is particularly pertinent in relation to women. In their daily lives women navigate ‘systematic structural violence rather than actual attacks’ (Koskela 1997,304; also Roestone Collective, 2014) that construct women as perpetual would-be 
victims. However, by focusing on fear, research can reproduce hierarchies of vulnerability that render the unsafe body as female.

In what appears to be the on-going pursuit of safety, there are relatively few empirical examples that interrogate the spatiality of what it means to be safe for women. In this article, we explore ways in which 'privileged' migrant women produce, experience and articulate safety in Singapore. Privilege here denotes the relative positioning of migrants within global hierarchies of power (Glick Schiller and Salazar, 2013). We see privilege as something which is not only possessed through intersections between gender, race and class in a given space, but draw upon work that critically examines how privilege is produced and practised (Fechter and Walsh 2010, Author 2017, Botterill 2016). The migrants we discuss in this paper are advantaged due to their socio-economic backgrounds, their ability to migrate, their desirability to the Singaporean knowledge economy, and their freedom to navigate urban space. During our research we were frequently questioned by other academics as to the 'point' of researching privileged migrants, that we should focus on the marginalised or the poor as subjects who are 'deserving' of our efforts. However, instead of directly problematising privilege, we think about what it could mean for future research agendas on the spatialisation of safety where we don't employ hierarchies as to who counts as research—or safe—-subjects. For example, by researching how privileged migrants come to feel safe, we can unpick their privilege and suggest how a spatiality of safety can be more widely researched and understood. Through this we contest scales of vulnerability - how women are considered to be inherently unsafe- - using the lessons applied here to think about how safety can be more widely practised. 
The paper therefore advances an account of what safety can look like. To do this, we utilise the metaphor of the 'expatriate bubble', a term that is popularly used among privileged migrants to denote disengagement from the local culture, and explore how different migrant bodies produce boundaries (Fechter, 2007). We extend the metaphor of the bubble to consider how it becomes used to denote separation from fear. The bubble allows us to explore how distinctions are produced and how these distinctions contribute to feelings of safety. The bubble therefore explores how 'expatriates' ${ }^{1}$ make distinctions and how these contribute to feelings of safety, enabling us to deconstruct how safety is made through privilege. We take up Kern's charge to explore 'sites of privilege' which contribute 'to greater feelings of safety in everyday life' (2005, p. 363) in order to understand the experiences of female privileged migrants in Singapore. We begin by reviewing the geographical and broader literature on fear and safety before outlining our methodological approach and findings.

\section{Fear}

To understand how safety is theorised we begin with a review of research into fear. Geographical work on fear has brought attention to the spatiality of fear of crime. Researchers note how fear of crime is embedded within social and political relations of different places and people’s individual experiences (Sparks 1992; Stanko 1990; Young, 1987). Arguably, political agendas at different times have influenced research interest into the spatiality of fear. In the eighties and nineties feminist geographers brought attention to the gendered nature of people’s experiences of fear (Valentine 1989). Research into women's fear of crime highlighted how women remain more fearful of crime than men, and often have a deep-seated fear of strangers in public spaces (Pain 1991), despite evidence that women are more likely to experience violent

\footnotetext{
${ }^{1}$ Expatriate is often used as a synonym for privileged migrant.
} 
assault within the home (Day 2001). This work prompted researchers to interrogate the complexities of fear, recognising it as borne out of individual experiences, structures of inequality, socio-cultural contexts and cultural narratives (Panelli, Kraack, and Little 2005). Furthermore, this work explored the intersectionality of fear, how it impacts upon different people's experiences of places (Pain 2001). For example, Day (1999) highlights how fear is mapped onto different spaces and intersects with gender, race and class.

Urban geographers have contributed to debates on the spatialisation of fear by considering how cities are navigated and experienced. For example, studies illustrated how fear shapes people’s mental maps - the routes they take or the places they avoid (Koskela 1997, Cahill 2000). As England and Simon (2010) note, the implications of fear reach beyond people's use of space, and influence urban policy and redevelopment. From this perspective, urban geographers demonstrate how policy responses seek to design out fear (Cozens, Saville, and Hillier 2005). For example, Hubbard (2004) notes how redevelopment agendas and gentrification permit some people at the exclusion of others. In doing so, neoliberal political agendas protect the interests of privileged groups through increasingly punitive and disciplinary urban design and institutional practices (MacLeod 2002). As such, cultures of fear, particularly in relation to marginalised groups, bolster revanchist gentrification agendas seeking to reclaim cities for white middle-class groups (Kern 2010).

More recently, fear has been conceptualised through geopolitical interventions on terrorism. Discourses of fear and terror pervade our everyday lives in ways that terror is made 'banal' through its continued reproduction in everyday life (Katz 2007). Others have explored the significance of terrorist discourses where cites are reimagined as 'homelands' in opposition to the ‘Arab Other’ (Graham 2006). As such, homogenous discourses produce a sense of imagined 
communities through a collective understanding of fear and the need to protect cities. But while geopolitical discussions of terrorism dominate public and policy discourse, others highlight the need for approaches that recognise the emotional implications of 'globalised fear' discourses (Pain, 2009). This work suggests that interest in terrorism at times fails to account for everyday implications of fear. It has also noted the disproportionate focus on terrorism in relation to other forms of violence that shape fear, for example domestic violence (Pain 2014).

Moves to address fear of terrorism can be seen to have legitimised encroaching surveillance and security measures in cities, for example increased CCTV, security checks or concrete infrastructure (Coaffee 2016). This work highlights the role of the built environment (Cozens, Saville, and Hillier 2005) in designing 'out' fear. For some, efforts to reduce the impact of a fear of crime results in greater demand for urban areas segregated from public spaces, where 'safety' is provided through the urban landscape—-such as walls, fences and security (Lemanski 2004, Geniş 2007). Within the context of expatriate migration, gated communities, stereotypically associated with privileged migrants explicitly and visually embody some of the ways that fear of crime can be seen to shape socio-cultural landscapes. Others have suggested that many of these concerns are rooted in racist fears of the 'Other' (Lemanski 2004). Reasons for gated communities vary. From a gendered perspective Kern's (2007) work on condominiums in Toronto highlights how the pursuit of safety is a key consideration for why women opt to live within these gated communities. In doing so, safety is commodified as an individualised choice, diminishing the perceived need for collective safety in public spaces, which reduces the prioritisation of women's safety on the public agenda. While addressing concerns regarding safety and security appears a primary reason for gated communities 
(Wilson-Doenges 2000), in other places, for example Saudi Arabia, they can be seen as a containment of expatriate culture (Mycoo 2006).

While feminist research agendas placed women's fear of crime at the centre of work in the early nineties, current geographical interventions have moved attention to the impact global scale issues - such as terrorism - have upon how people navigate fear in the everyday. Urban geographers contribute to these discussions by looking at how fear is mapped onto, and can be designed out of, urban spaces. Therefore, while discussions of safety, or the pursuit of safety, may dominate popular discourse, it appears that this is only often possible through continued reference to fear.

\section{Safety}

So far we have explored scholarship on safety in relation to the absence of fear, rather than focussing directly on the emotional experiences of safety itself. Discussions of safety itself are inherently gendered. For women, methods of 'safe-keeping' (for example, ways of dressing, talking or walking routes) can be considered normative aspects of modern femininity or as practices of ‘doing gender’ (Campbell 2005, Moore and Breeze 2012). For many women, methods of staying safe are internalised and performed. As such, feeling safe can be the result of active strategic knowledge that requires the ability to locate and practice safety in different spaces resulting in routines becoming embodied (Stanko 1997).

Practices of safety, or the ability to feel safe, are situated within particular contexts or identities. In her work on the night time economy Fileborn (2016) highlights how safety practices focus on the familiar. For her participants, familiarity encompasses both people and 
places - not only people known to them but that appeared to be like them. Familiarity - and therefore safety - was produced through constructing bounded safe and known spaces to the exclusion of other places (and people). This work highlights how fear of otherness and strangers can provoke feelings of insecurity and anxiety (Panelli, Kraack and Little 2005, Amin 2012). Safety is seen to be produced and experienced differently in relation to intersecting identity markers. In her work on safety, race and gender, Kern (2005) highlights how gendered oppressions may reduce privileged women's ability to feel safe in public space - for example through street harassment. However, their subject positions in relation to race and class may provide them with access to spaces, through a sense of entitlement, that are ethnically and economically diverse in ways that 'other' women may not be able to (Kern, 2005). As such, research should recognise women's contradictory subject positions in relation to safety, and the significance of privilege in women's negotiation of urban spaces.

It is important to understand safety as more than just the absence of fear. While difficult to define, research has focused on safety in its own right, providing the opportunity to explore people's broader and more positive experiences of wellbeing in different places (Hutta 2009). Work in this area recognises the subjective and embodied sensations of emotions and how they are situational, relational and transient (Davidson, Bondi, and Smith 2005). In their work, Brands and Schwanen (2014) argue that safety is unconscious and that it is only until this is disturbed that people articulate fear. However, while we acknowledge the importance of exploring the range of ways safety is felt beyond fear, we argue that their proposition ignores the role of privileged identity positions in shaping how people construct and embody safety. 
Many people find safety through the exclusion of others. In their work on 'expatriates', Van Bochove and Engbersen (2015) use the expatriate bubble to refer to exclusionary practices of migrants-living homogenous lifestyles, in gated communities, associating only with other people like them. Researchers exploring the practices of privileged migrants explore how the familiar shapes migrant lives. For Butcher (2010), one of the practices of Australian migrants in Singapore is to recreate home through friendship practices that focus on people with similar backgrounds. Previous articulations of the 'expatriate bubble' highlight the ways migrants seek to guard themselves from the unfamiliar through practices that exclude others (Fechter 2007). For example, in China, Yeoh and Willis (2005) argue that the activities, practices and networks of the 'community of transnationals' are replications of familiar national practices which are utilised to keep a distance from the local. While not explicitly articulated as safety, this illustrates some of the ways in which practices of safety have a geography.

In other work, researchers demonstrate how safety is distinctly spatialised. From a political perspective, 'safe spaces’ have been used to denote physical spaces where marginalised groups may feel safer to engage and participate in discussions or activities, often particularly in relation to women only spaces (Lewis et al. 2015). Researchers illustrate how these spaces are produced relationally to unsafe spaces, often taking on a symbolic form (Roestone Collective 2014). Yet, safe spaces 'often fail to critically engage with the paradigms that underline harassment and discrimination’ (Roestone Collective 2014, 1352), acting as a physical separation from the mainstream. By separating safety from mainstream/normal space and time, they do little to offer a conceptualisation through which safety can be produced more broadly. The search for safe space appears intrinsically tied to fear. Whether it is women's refuges for those fleeing domestic violence (Hester 2011) or placing children in secure units to 'protect' them from 
abuse and harm (Hallett 2015), 'safety' is often created through restrictive practices and punitive approaches to place.

In synthesising existing research on fear and safety we can see several clear tropes. The first is the ways research focuses on vulnerability, reproducing the idea women experience fear of crime. The second is the way fear is produced through the idea of the Other. For example, the expatriate bubble speaks to ways in which 'expatriates' build boundaries in order to keep the unfamiliar out. However, both vulnerability and Othering work differently depending on who you are. Through the rest of this paper we take up this point to focus on privileged migrants, demonstrating how safety is produced as an embodied experience in Singapore.

\section{Methodology}

This paper draws upon two research projects. The first project carried out by Sophie Cranston, was designed to examine the ways through which British migrants in Singapore understood themselves as expatriates. Carried out between February and April 2012, the research involved 36 individual interviews with 39 British migrants as well as ethnographic observation. $79 \%$ of the participants were male and $92 \%$ white. Although safety was not a formal part of the interview schedule, this theme was repeatedly articulated by the respondents. The second project, carried out by Jenny Lloyd, explored expatriate women's embodied experiences of migration with a focus on body size. The empirical research was carried out between September 2012 and March 2013. 45 interviews were carried out with women that self-identified as expatriates and one focus group with five women. While participants came from 12 different countries $50 \%$ of those interviewed were British and $72 \%$ identified as white. It is important to note that not all our participants were white, as is often assumed in accounts of privileged migration (Cranston, 2017). 
As British females in Singapore, we embodied a similar positionality to our research subjects. Certainly, our experiences of negotiating and navigating Singapore were marked by similar perceptions of safety that were discussed by our respondents. For example, in Author's A experience, male respondents would reference the researcher's safety-that Singapore was a safe space to negotiate as a lone woman researcher. Having a common point of experience with our respondents, for example, in feeling comfortable walking around the streets late at night, meant that the meanings of safety were often a detailed point of discussion. Furthermore, the context of Singapore has significant implications to how our participants articulated and understood safety. Popular press and discourse continually references Singapore as one of the safest countries in the world (The Independent 2017). Simultaneously, the Singaporean government have a reputation for enforcing punitive sanctions and approaches to law enforcement; Singapore has one of the highest rates of executions per capita worldwide (Amnesty International 2017). It is within this context that our participants narrated safety.

In taking the data from each of these two projects together, we analysed our transcripts looking for ways in which both safety and fear were actively produced. This was carried out using a discourse analysis, looking for repetition of themes, which were utilised as codes, and exploring their context. In the following three sections we present the empirical findings to argue that the expatriate bubble also works to create safety for women. Using the metaphor of the expatriate bubble we explore how safety was constructed (building the bubble) and experienced (being in a bubble) before deconstructing these, focussing on Othering (bursting the bubble). 


\section{Building the bubble}

In this section, we look at the ways in which the 'bubble' is actively produced for, and by, privileged migrants in Singapore. It focuses on the ways participants made distinctions between Singapore as the 'bubble' and spaces on the outside: both Asia and 'home.' This is similar to a process described by Pain (2000) as 'distancing,' the 'geographical and social distancing of threat which many people employ to feel safer' (p373). Our respondents suggest crime does not happen to them in Singapore, that is, crime is something that happens elsewhere. However, this section will illustrate two differences in how our respondents 'build the bubble' in Singapore to previous work on safety and fear: first, Singapore is seen to be marked not just by an absence of fear, but safety in its own right; second, safety is seen as the unfamiliar.

The key way the 'bubble' is built is through a perception of a low crime rate in Singapore: “The other thing here is the safety. You don't hear much about crime” (Lucy, white). Crime is usually seen as a direct cause of fear, however, our respondents discussed crime directly in relation to safety. James highlights this when discussing what he knew about Singapore before he arrived: "But I knew it was squeaky clean and I knew that everything worked, that it was relatively safe and low crime and I sort of, I knew that it would all be fairly easy” (white). Therefore, safety is present in itself. The distancing of crime elsewhere contributes directly to a presence of safety, not an absence of fear.

Such discussions often suggested that safety was a result of strict laws in Singapore. Participants noted how their perception of Singapore as having no tolerance to crime affected their sense of safety and security. While discussions did arise relating to the authoritarianism of the Singapore state, for some, particularly women, they appeared happy to accept the 
encroachment of surveillance and punitive laws ${ }^{2}$ in return for what they considered the benefit of heightened feelings of safety. Many celebrated and enjoyed the freedom to feel safe. But this was often discussed as at the expense of other freedoms and rights. This freedom paradox was most commonly discussed in reference to the supposed ban on chewing $\operatorname{gum}^{3}$ :

for me having children I think that [Singapore's] great but at the same time, I'm like I wanna chew gum, I can't chew gum and I found some on my husband's nightstand and I was like Oh my God [joy]. (Hazel, East Asian).

While some participants recognised that in some ways Singapore's strict rules inhibited them, it was therefore often considered a justified trade-off if it afforded them greater 'freedom' in terms of their ability to feel safe and not to worry about their children:

It's very safe as well I think it's a good thing if you're outside on your own at in the evening it's very safe. It has a lot positive things in that sense, and I remember when we were moving here people were like 'oh are you're crazy they're so strict it's almost like a dictatorship, you're not allowed to go and demonstrate' and I was like so what, I'd rather not be allowed to go and demonstrate [...]Here I'm a lot more relaxed, if a kid is kidnapped, if anything happens to a child it's death sentence, because they have such strict laws. You know that's it, it deters people from doing things. Although I wouldn't break the law here. I would be extremely scared of the outcome and what would happen in jail. I think it’s very good because it becomes very safe. It helps in that sense. (Alda, white).

Discussions of strict consequences, such as the death penalty, were not the only way that regulations affected privileged migrant's experiences of living in Singapore. While many

\footnotetext{
${ }^{2}$ Singapore's punitive laws impact all Singapore residents, including privileged migrants. Despite examples of privileged migrants receiving penalties for crimes such as vandalism and fighting, journalists report that 'rich foreigners' receive more lenient sentencing than Singapore nationals (Straits Time Review, 2018) which could be read as a manifestation of their privilege. The law Alda references is a ban on protest without a license from the Government, however, foreigners are not able to protest at all. This includes participating in events like the pink dot, which supports homosexual rights in Singapore.

${ }^{3}$ There is a ban on the sale of chewing gum in Singapore. This was often used colloquially by our respondents to describe the Singaporean Government as strict.
} 
interviewed discussed feeling a sense of ‘freedom’ from living in Singapore (see below), it is clear from some discussions that this was not reflected in all aspects of people's lives. For some women, being in the bubble is a trade-off between their sense of safety and other parts of their lives. For example, while many women discussed feeling 'liberated' by their ability to walk freely, many reflected on how their statuses as 'dependents' resulted in them feeling limited (Author B, 2017) 4: 'when you're a dependant, you're not really technically a person' (Anita, South Asian). While the visa status of those interviewed was not dependent on gender, women were much more likely to be on dependent passes, and therefore restricted in what they could do. ${ }^{5}$

Singapore's low crime rate does not in itself constitute a bubble. While the relative freedom afforded by low crime did appear to significantly contribute to enhanced feelings of safety, the bubble was also produced through exclusionary practices. The bubble as a 'safe space' is produced relationally, through comparisons made between Singapore and other locations. For example, Singapore is compared with other locations in Asia, where fear of crime is seen as an issue. This is something that Gina suggests comes as a surprise to her 'Even like security, you go back home and you go ‘oh shit yeah I have to watch my bag' in Vietnam’ (white). Low crime also contributes to another way in which Singapore as a space is produced through discussions of Singapore as being 'easy Asia': 'Singapore is an easy place in Asia is an easy place to start right, Asia for beginners. It's the easiest place in Asia to live I think' (Sonja, white). That is, the feelings of safety made Singapore feel easy, compared to Orientalist assumptions of what Asia should be like (Cranston, 2016).

\footnotetext{
${ }^{4}$ A Dependent Pass is the visa that allows spouses and children to accompany those on an Employment Pass. Participants discussed challenges in finding employment and administrative challenges such as the inability to make changes to, or access, their banking accounts.

${ }^{5}$ This is not the case for all migrants. Domestic worker visas are only granted to women [Ministry of Manpower 2018].
} 
Others illustrated how the bubble is produced through comparisons made between Singapore and the United Kingdom ${ }^{6}$ :

'It's very hard to go from, one in the middle of Swansea knowing that there's nutters out there, to one walking around Clarke Quay' (Cath, white)

'when I was in the UK, even, wherever I go with the kids I have this constant fear that something would happen to them or someone would take them' (Anne, white).

Both of these women articulate the difficulty they feel in returning to a space where, compared to Singapore, they experience fear of crime. Whilst Singapore as Easy Asia articulates Singapore as being similar to the United Kingdom, for Cath and Anne, it is also different from the UK in terms of feeling safe. This complicates the ways safety is understood-in this example, it is the unfamiliar perception of low crime that results in Singapore being produced as safe.

In building the bubble, privileged migrants in Singapore displace crime, and the fear of crime to other spaces_-other areas in Asia and their home countries. This works to locate fear as being something associated elsewhere (Fileborn, 2012, Pain, 2001). In this way, the 'bubble' of Singapore acts as a space of safety, one produced relationally to fear which is located elsewhere:

'It's just a very clean and safe environment from somebody who is out here on your own. I have no fear at all. In fact I think you get quite lax. Cos when you travel to other places you need to remember that actually you need to be a bit more careful with our belongings' (Martha, white).

\footnotetext{
${ }^{6}$ We use the UK here as an example as this is the nationality of the majority of our respondents. Similar comparisons were made between Singapore and other 'home' countries.
} 
Leaving Singapore is like leaving the bubble of safety. This illustrates the scale of Singapore as a safe space. As privileged migrants displace crime elsewhere, the bubble is articulated at the city-scale as opposed to a distinct space within the city, like a gated community. In this way, the building of the bubble by privileged migrants reinforces understandings of a separatist safe space that is produced relationally to unsafe space (Roestone Collective, 2014). However, the bubble is discussed as a presence of safety_imagined through discussions of the low crime rate-as opposed to an absence of fear. This is why the unfamiliar, which is often seen to result in fear, becomes a way through which to understand safety.

\section{Being in a bubble}

Participants often used the metaphor of 'being in a bubble' to describe migrant experiences of living in Singapore or more generally to refer to Singapore itself. Primarily, discussions of safety centred on the absence of fear of crime, which for many, appeared to contribute to embodied experiences of safety. In this section, we look at how the bubble and gender intersect: first, we look at how women articulated an embodied sense of safety; second, we look at how men discuss safety in Singapore as being a space for women.

The significance of feeling safe was most frequently discussed by women. For women in particular, this was a unique experience for them, resulting in feelings of safety and freedom from the constraints of safety precautions they may employ at home. While not always explicitly stated, it was implied that the women were often discussing safety in reference to male violence and in particular, sexual assault. The most frequent way that participants suggested how feeling safe was embodied and practised in their everyday lives was through discussions of being able to walk freely around the city: 
And that's the good thing being a single female or on your own here because you can go out at any time of day as long as you're fairly sensible and don't go down a back way you're totally fine. You come home through parks here at four in the morning down Orchard [Road]. You would never think of going out on my own and being worried (Gina, white).

Freedom to walk around the city was only reflected on by women or by men about women. Inherent within these discussions is reference to the practices of safekeeping that women employ in their home countries, for example feeling like they could not walk home at night without other people or avoiding certain areas (Stanko 1997). Although Gina still acknowledges a practice of safety, she articulates a freedom of feeling able to walk through a park at night, a space in Western societies which is seen as inherently fearful (Fileborn, 2016). While often an ingrained aspect of women's everyday experiences of public space the notable absence of fear was a liberating experience for many women:

And that I think is, like going abroad or going back home, umm, I think I'd miss how safe it is here, because you can just walk around at any time of night or day (Jade, white)

It is clear that women have absorbed messages about how to 'keep safe' to extent that they are recognised as common-sense and mundane aspects of being a woman (Brooks 2011). Yet in Singapore, being in a bubble, allows women the freedom to walk around without fear of male violence. However, it was also clear from interviews that this 'bubble' represents a temporary liberation from the constraints of fear spatialised in Singapore, and that it is therefore important that migrants, and women in particular, are still capable of practicing safety when they leave Singapore. The idea of safety as embodied practice was highlighted by several participants:

So how would I find it different from the UK? Well I actually feel safe here. I have no problem walking around by myself at night and getting a taxi. And I don't worry about my safety. [...] it’s noticeable now when I go back to Newcastle. And it’s a bit like ooo. 
But I do think you get stuck in this bubble out here, that's what the problem is, you are stuck in this little bubble. And you just, it’s quite easy to get relaxed, and when I get home I'll hang onto my handbag. (Sophia, white).

Embodied practices of safety and how this was reduced in Singapore were referred to in several ways. Most of these discussions focused on protecting oneself from theft. While many of the women were happy to talk about their freedom to walk in Singapore at night, fewer seemed comfortable talking explicitly about the threat of sexual harassment and assault that is suggested elsewhere when discussing feeling safe in Singapore. This suggests that fear of sexual assault, what Gordon and Riger (1989) define as ‘female fear’ is often implied rather than explicitly discussed. While elsewhere, safety measures often rely on increasing punitive or restrictive approaches to space, safety in this context - for privileged migrantsfacilitated a temporary sense of freedom, even if this was not truly the case.

Throughout discussions, with both men and women, it was clear that gendered understandings of safety play a role in the reasons participants had for moving to Singapore. Within this, there is an inherent understanding that women are unquestionably in greater need of protection in public spaces. This is an idea perpetuated by men:

It's clean, it's safe and it's pretty strict. But when I moved I had three youngish daughters so it being safe was an attraction. (Luke, white)

I came here for the opportunity of working, came to set up [company], I stayed because it's easy, it's very safe, very secure. There is nothing wrong with Singapore. I have no concern if my wife is out until 12 O'clock at night making her own way home, no concern with that. (Henry, white)

While well intentioned these discussions hint at what Glick and Fiske (1996) define as 'benevolent sexism'. Although the concern men have for women may be considered positive and caring it is grounded within a shared understanding of women as in need of protection. The 
repetition of these narratives rationalises greater restrictions placed upon women, which ultimately become justified and normalised over time (Moya et al. 2007). As long as women are seen as more vulnerable to the threat of crime, and in particular rape, men's dominance as protectors will be preserved, as will women's willingness to be protected (Phelan, Sanchez, and Broccoli 2010). It is most clear in the comments by Luke and Henry that women are still considered most at risk with an inherent sense that women should not walk alone. This reproduces gendered understandings of safety, reinforcing narratives that women's bodies are the location of fear, which is temporarily disrupted while cocooned in the bubble in Singapore.

There are gendered differences here in how safety and 'the bubble' are experienced. While it was clear that 'being in a bubble' and the relative safety felt by women in Singapore afforded them a new-found freedom to walk and live without fear, this was not necessarily the case for many privileged men. Feeling safe was often seen as something that women needed, while some of the men interviewed felt a greater need for 'adventure':

The expats that are coming out now are umm expecting much more comfort, they don't come for the adventure, they come out as a job. It's London or Singapore, well if I am going to Singapore then I want a nice flat and this and that, and my wife is pregnant and it is a nice safe place to have a baby so yes that will be alright. Whereas us older expats saw it something of an adventure to be honest, to be working in the sand dunes, or jungle or whatever. (Andrew, white)

Andrew associates the bubble with comfort and safety, suggesting that these are needed by wives and children. Yet underlying this, and in several interviews with men, it was suggested that safety was considered boring, and danger was equated for many men as adventurous. In particular Andrew's discussion reflects traditional colonial narratives of adventure and imagined geographies of the 'exotic other' (Fechter, 2016). Yet for women, safety represented freedom to live without fear of violence. For many men, the bubble and safety 
were considered to minimise the sense of adventure of living abroad, while for women safety was experienced as freedom from their everyday experiences of fear of assault in their home countries. Therefore, we can consider how the embodiment of safety is gendered and spatially constituted (Valentine 1989). In the following section we further deconstruct some of the ways that safety was produced for privileged migrants.

\section{Bursting the bubble}

We have seen how safety was embodied, where women's bodies in Singapore became liberated from fear. We focus now on the intersections between the body and the safe space of the 'bubble.' In this section, we focus on how privileged migrants in Singapore discuss race in relation to the bubble, 'bursting' the bubble by illustrating how privileged migrants distance themselves from locals. In contrast to previous research on fear, it illustrates that the presence of a racialised Other is not seen to produce fear which translates into the practices of these privileged migrants.

Previous research suggests that the presence of a racialised Other challenges a sense of safety. As such, the embodied navigation of safety is racialised; Kern (2005, p. 367) argues that 'whiteness and other privileged social locations construct a sense of belonging' which result in feelings of safety by crafting a sense of familiarity. Koskela (1997) suggests, women often feel more comfortable and safe in spaces they feel at home in. As she suggests, 'routinising space' (p309) through using space daily, reduces the fear associated with it. We can see similar tropes in Singapore, through practices of safekeeping where privileged migrants inhabit space which imbue an 'expatriate sense of place' (Beaverstock 2011, 247). While many of the women appeared to enjoy the freedom to walk around it was apparent in several interviews that feelings of safety were mapped onto certain areas: 
We went shopping in Tiong Bahru and that felt the same, there weren't as many expats just locals and you just didn’t feel like you belonged as much but here around Orchard you feel just completely comfortable because there are so many expats here (Claudia, white)

Therefore, Orchard Road, a high-end Westernised shopping street, is considered to be a relatively safe space for privileged migrants to walk freely around in comparison to Tiong Bahru, a residential area with Asian architecture. Claudia suggests that she feels less comfortable in areas which are less familiar to her, a similar logic to practices of familiarity discussed above.

This can also be seen through discussions of race, which are spatialised into various areas of Singapore. In thinking about the mapping of safety in Singapore, migrant women noted their discomfort in areas outside an expatriate sense of place:

Little India is about the only place I don't particularly feel comfortable. Geylang7 is the other one because we've got Geylang up here which is very. Cos I go up into Geylang because there is a great cake supply shop, um so I will often trek up there but you do feel conspicuous you do feel conspicuous (Alba, white).

So there's a lot of older people older Chinese. Sometimes you go up there and you can hear 'ang mo' 'ang mo, ${ }^{8}$ ' looking at you and you don't feel that comfortable in places. Some of the old folk really don't like white people (Christina, white).

Alba and Christina relate their discomfort to their visibility, feeling 'conspicuous' or being ascribed as an Ang Mo, or a white person. However, neither Alba nor Christina suggest that they don't feel safe, or that they feel fearful. It could be argued then, that their discomfort is derived from being marked as raced, as Fechter (2007) argues, as being ‘deviant' from the

\footnotetext{
${ }^{7}$ Geylang is the Red Light District of Singapore.

${ }^{8}$ Ang Mo is the Hokkein dialect phrase for a 'white person.' It translates literally as red face or red hair.
} 
norm. White people in contexts like the UK are privileged in their racial identities through the way in which this is normalised, being seen as unraced (Kern 2005). In Singapore, it is the visibility of white migrants that marks them as the Other. However, this does not work to 'burst' the bubble in terms of their feelings of safety, rather it challenges their sense of ontological security.

In these discussions, we can see how racial difference, or the Other, results in a discomfort of feeling visible, but this does not threaten embodied feelings of safety. The presence of the Other does not result in fear. For example, Sharon made the comparison between her car breaking down in the UK and in Singapore:

now if my car broke down there I'd be petrified, whereas here if my car broke down here in the middle of that [area] with 3,000 million Indians and Pakistanis and Singaporeans and Chinese, I wouldn't even worry one bit because nobody would hurt you, they would actually help you, they'd be like can I help you and there wouldn't be anything sinister in it. And that I think is just one of the most amazing thing about Singapore, is that as a woman you can, do, you are free, and you can do the things you want to do and it's amazing (Sharon, white).

Sharon highlights her fear of being unexpectedly stranded in the UK, a fear that she doesn't have in Singapore even though there is a large number of 'Others.' That is, despite the presence of the Other, Sharon exemplifies how safe she feels. Sharon shows that the bubble isn't an individual experience, but is mapped onto all of Singapore. She feels she can travel freely, making Singapore and her own position within it a bubble.

Discussions about the relationship between race and safety were moved from the space of Singapore onto other bodies. Safety then was racialised in a different way, away from the privileged migrant's body. As highlighted above, it is incorrect to assume that crime doesn't 
happen in Singapore. While most participants reflected on greater feelings of safety and suggested that Singapore was safer for women in particular, this appears to be in the absence of recognition of forms of abuse and violence that happen to 'other' women in Singapore most notably those who are different to them. In the following quotes, Martha highlights that domestic violence happens in 'little communities' away from expats and Hazel to domestic worker migrants who occupy different class structures:

So I think here, there is crime, and I think there is violence and I think there's domestic abuse but I think it's very much in little communities. Whereas I think that's why expats don’t really see it because it never effects them, you know you won’t be slapped in the street and have your bag snatched, that won’t happen. (Martha, white)

That's one of the things I really don't like about Singapore. We always try to make sure our helper is treated with respect, and she is our helper but at the same time she's a human being, she's a woman, because there was an incident where she was solicited at the temporary residence. By one of the gardeners, Chinese gardeners, I was very upset about that, he was removed from the premises by the manger but um yeah I was, it was just horrible. (Hazel, East Asian)

Safety is not something that is assumed for all people, but instead violence is seen as something that is experienced by women outside of the privileged migrant community and therefore by and to 'others'. In doing so, participants distance violence through the assumption it is something separate from privileged migrant's experiences. While Martha and Hazel recognise that violence towards women does happen, it is seen as something separate to them. This is a product of the expatriate bubble which constructs some women, and the violence they experience, as separate to the experiences of privileged migrants, by reproducing racist narratives of violence as cultural phenomenon and not the responsibility of society as a whole (Jamal 2008, Berns 1999).

Singapore, as a safe space, can be seen as racialised and produced through notions of the 
Other. This is produced, not in relation to the migrant's body, or race, but to Other unseen bodies. By producing the bubble as a safe space, the privileged migrants who inform this paper are reproducing their privilege onto the landscape of Singapore. In some ways, they perform the idea of safety. The frequent discussions of safety act as a way through which safety is reaffirmed as opposed to denied. Their existence in a bubble means that they do not want the idea of safety to be challenged by those bodies who are rendered 'unsafe.' This makes these migrants privileged; their ability to re-locate crime away from their bodies, and their embodied practices of navigating Singapore, onto bodies who are completely separate from themselves.

\section{Conclusion}

Through this paper we have questioned what a safe space is for women, how it is produced and experienced. Focusing on female migrants to Singapore we illustrated how their privilege works to place them in a 'bubble,' one that enables them to embody safety. This, we argue, reveals more about the ways in which we can understand safety than fear. The experiences of the women discussed in this paper still exhibit signs of the scales of vulnerability that place the women's body as the location of fear. However, Singapore is seen to be a safe space despite the fact they are women and despite the presence of the Other. The feelings of being safe in Singapore or 'in a bubble' are related to privilege. Arguably, the central way these women are privileged is in their negotiation of their everyday lives—feeling safe by denying the experiences of others. By focusing on safety rather than simply interrogating privilege, this allows us to critically evaluate two points.

First, one of our goals is to think about how we develop safer societies more broadly. Safety in itself must be understood as something more than the absence of fear, but a feeling and 
practice in its own right. This involves developing research agendas that focus on safety and can critique what safety means for different groups. The women migrants presented in this research highlight a contradiction to ways through which this can be achieved. For example, one of the ways the bubble is produced by these women, deflecting fear onto other bodies, is a means by which they negate any responsibility for crime-something that happens in other communities. In some respects, the safety these privileged migrants feel is dangerous as it allows them to live in a bubble-like existence disconnected from issues that affect other people. However, safety cannot be considered realised until it becomes a reality for all people. This means researching other experiences and appreciating other narratives of safety to develop an understanding of what safety can mean, and look like, for all.

This appreciation of viewpoints goes two ways. Empathy for other perspectives is an important part of feminist work, to understand issues as being relational (Parker, 2016). The \#metoo movement in 2017 highlighted some of the day-to-day challenges of being a woman; the pervasiveness of sexism in the workplace, daily experiences of sexual harassment and the widespread threat of sexual violence. What this movement has done is started a conversation, one that links women of different backgrounds, be it the office cleaner and the teacher, to the politician or the Hollywood actor - through shared experiences of fear. These discussions often lead us to question what it is to live safely. Yet in a moment when many women are connected, we must not assume that all experiences are the same. Violence, or the threat of violence, may pervade many women's lives. Our ability to live safely is intimately connected to our position within society, our privilege, or lack thereof in different places. The momentum from movements like \#metoo should mean that as academics we work together to think about how safety is produced for all and as feminists work together to think about how safety can be produced for everyone. 
Second, this paper can help reinvigorate discussions about safety. The literature review highlights how research in the late 1990s and early 2000s focused on fear exposed gendered uses of space, but has since dipped in popularity. The majority of continued interventions take place in feminist journals like Gender, Place and Culture, making this seem as if it is only a feminist issue. Meanwhile, discussions of fear have shifted in focus to global terrorism and the fear of the Other-something that we can suggest as a reflection of changing political agendas, and the desire for academics to produce the type of the 'impactful' and 'timely' research that is attractive to funding bodies, REF panels and promotion boards. While this is, by no means, an attempt to discredit the important work that has looked at safety in the past two decades, we suggest that following policy relevant research does not negate issues that fall out of fashion. Women's (lack of) safety has not gone away. With the \#metoo movement, this is likely to be back on the policy agenda. With this, we hope that academics will have the time and momentum to put safety—as opposed to fear—for women on the research agenda. By looking at how women feel safe, we come from a position not of vulnerability, or of being marginalised, but think instead about how safety can enter both the mainstream of a research agenda, and become a mainstream embodied practice.

\section{References}

Author B, 2017

Amin, A. 2012. Land of strangers. Cambridge: Polity. Amnesty International. Singapore: Executions continue in flawed attempt to tackle drug crime, despite limited reforms 2017 [cited 1st February 2018. Available from https://www.amnesty.org/en/latest/news/2017/10/singapore-executions-continue-inflawed-attempt-to-tackle-drug-crime/. 
Beaverstock, J. 2011. "Highly Skilled International Labour Migration and World Cities: Expatriates, Executives and Entrepreneurs." In International Handbook Of Globalization And World Cities, edited by B. Derudder, M. Hoyler, P. J. Taylor and F. Witlox, 240-250. Cheltenham: Edward Elgar.

Berns, N. 1999. "“My problem and how I solved it”: Domestic violence in women's magazines." The Sociological Quarterly no. 40 (1):85-108.

Botterill, K. 2016. "Discordant lifestyle mobilities in East Asia: privilege and precarity of British retirement in Thailand." Population, Space and Place. Online First.

Brands, J., Schwanen, T. 2014. "Experiencing and governing safety in the night-time economy: Nurturing the state of being carefree." Emotion, Space and Society 11:6778.

Brooks, O., 2011. 'Guys! Stop doing it!': young women's adoption and rejection of safety advice when socializing in bars, pubs and clubs. The British Journal of Criminology, 51(4), pp.635-651.

Butcher, M., 2010. From 'Fish out of Water' to 'Fitting In': the challenge of re-placing home in a mobile world. Population, Space and Place, 16(1), pp. 23-36.

Cahill, C. 2000. "Street literacy: Urban teenagers' strategies for negotiating their neighbourhood." Journal of youth studies no. 3 (3):251-277.

Campbell, A. 2005. "Keeping the 'lady' safe: The regulation of femininity through crime prevention literature." Critical Criminology 13 (2):119-140.

Coaffee, J. 2016. Terrorism, risk and the global city: Towards urban resilience: Routledge.

Cozens, P.M., G. Saville, and D. Hillier. 2005. "Crime prevention through environmental design (CPTED): a review and modern bibliography." Property Management 23 (5):328-356.

Cranston, S. (2016) 'Imagining Global Work: Producing Understandings of Difference in 'Easy Asia,' Geoforum 70 60-68.

Cranston, S. (2017) Expat as Good Migrant: Thinking through Skilled Migration Categories, Population, Space and Place. Online First.

Davidson, J., Bondi, L. Smith, M. 2005. Emotional geographies. Aldershot: Ashgate.

Day, K. 1999. "Embassies and sanctuaries: women's experiences of race and fear in public space." Environment and Planning D: Society and Space no. 17 (3):307-328.

Day, K. 2001. "Constructing Masculinity and Women's Fear in Public Space in Irvine, California." Gender, Place \& Culture 8 (2):109-127

England, M. R., Simon, S. 2010. "Scary cities: urban geographies of fear, difference and belonging." Social \& Cultural Geography 11 (3):201-207.

Fechter, A.M., 2007. Transnational Lives: Expatriates in Indonesia. Aldershot: Ashgate.

Fechter, A.M. (2016) Mobility, white bodies and desire: Euro-American women in Jakarta. The Australian Journal of Anthropology, 27 (1). pp. 66-83.

Fechter, A.M. \& Walsh, K., 2010. Examining "Expatriate" Continuities: Postcolonial Approaches to Mobile Professionals. Journal of Ethnic and Migration Studies, 36(8), pp. 1197-1210.

Fileborn, B. 2016. "Doing gender, doing safety? Young adults' production of safety on a night out." Gender, Place \& Culture 23 (8):1107-1120.

Geniş, Ş., 2007. Producing elite localities: the rise of gated communities in Istanbul. Urban Studies, 44(4), pp.771-798.

Glick, P. and Fiske, S.T., 1996. The ambivalent sexism inventory: Differentiating hostile and benevolent sexism. Journal of personality and social psychology, 70(3), p.491. 
Glick-Schiller, N. \& Salazar, N., 2013. Regimes of mobility across the globe. Journal of Ethnic and Migration Studies, 39(2), pp. 183-200.

Gordon, M.T., Riger, S. 1989. The female fear: The social cost of rape: University of Illinois Press.

Graham, S. 2006. "Cities and the 'War on Terror'." International Journal of Urban and Regional Research no. 30 (2):255-276.

Hallett, S. 2015. "'An Uncomfortable Comfortableness': 'Care’, Child Protection and Child Sexual Exploitation." British Journal of social work no. 46 (7):2137-2152.

Hester, M. 2011. "The three planet model: Towards an understanding of contradictions in approaches to women and children's safety in contexts of domestic violence." British Journal of Social Work no. 41 (5):837-853.

Hubbard, P. 2004. "Revenge and Injustice in the Neoliberal City: Uncovering Masculinist Agendas." Antipode no. 36 (4):665-686. doi: 10.1111/j.1467-8330.2004.00442.x.

Hutta, J.S. 2009. "Geographies of Geborgenheit: beyond feelings of safety and the fear of crime." Environment and Planning D: Society and Space no. 27 (2):251-273.

Jamal, A. 2008. Diffusion of Responsibility: A Discourse Analysis of the Toronto Star's Portrayal of Domestic Violence in the South Asian community. Mémoire inédit de maîtrise. Ryerson University.

Katz, C. 2007. Banal terrorism: Spatial fetishism and everyday insecurity. Routledge New York.

Kern, L. 2005. "In place and at home in the city: Connecting privilege, safety and belonging for women in Toronto." Gender, Place and Culture 12 (3):357-377.

Kern, Leslie. 2007. "Reshaping the boundaries of public and private life: Gender, condominium development, and the neoliberalization of urban living." Urban Geography no. 28 (7):657-681.

Kern, L. 2010. "Selling the 'scary city': gendering freedom, fear and condominium development in the neoliberal city." Social \& Cultural Geography no. 11 (3):209-230.

Koskela, H. 1997. "'Bold Walk and Breakings': Women's spatial confidence versus fear of violence." Gender, Place and Culture: A Journal of Feminist Geography 4 (3):301320.

Lemanski, C. 2004. "A new apartheid? The spatial implications of fear of crime in Cape Town, South Africa." Environment and Urbanization 16 (2):101-112.

Lewis, Ruth, Elizabeth Sharp, Jenni Remnant, and Rhiannon Redpath. 2015. "'Safe spaces': experiences of feminist women-only space." Sociological Research Online no. 20 (4):1-14.

MacLeod, G. 2002. "From urban entrepreneurialism to a "revanchist city”? On the spatial injustices of Glasgow’s renaissance." Antipode no. 34 (3):602-624.

Ministry of Manpower (2018) Foreign domestic worker eligibility. cited 13th February 2018. Available from http://www.mom.gov.sg/passes-and-permits/work-permit-for-foreigndomestic-worker/eligibility-and-requirements/fdw-eligibility

Moore, S.E. and Breeze, S., 2012. Spaces of male fear: The sexual politics of being watched. British Journal of Criminology, 52(6), pp.1172-1191.

Moya, M., Glick, P., Expósito, F., De Lemus, S. and Hart, J., 2007. It's for your own good: Benevolent sexism and women's reactions to protectively justified restrictions. Personality and Social Psychology Bulletin, 33(10), pp.1421-1434. 
Mycoo, M. 2006. "The retreat of the upper and middle classes to gated communities in the poststructural adjustment era: the case of Trinidad." Environment and Planning A 38 (1):131-148.

Pain, R. 1991. "Space, sexual violence and social control: integrating geographical and feminist analyses of women's fear of crime." Progress in Human Geography no. 15 (4):415-431

Pain, R. 2000. "Place, social relations and the fear of crime: a review." Progress in Human Geography 24 (3):365-387

Pain, R. 2001. "Gender, race, age and fear in the city.” Urban Studies 38 (5-6): 899-913.

Pain, R. 2009. "Globalized fear? Towards an emotional geopolitics.” Progress in Human Geography. 33(4): 466-486

Pain, Rachel. 2014. "Everyday terrorism: Connecting domestic violence and global terrorism." Progress in Human Geography no. 38 (4):531-550.

Panelli, R, Kraack, A., Little, J. 2005. "Claiming space and community: Rural women’s strategies for living with, and beyond, fear." Geoforum no. 36 (4):495-508

Parker, B. 2016. Feminist Forays in the City: Imbalance and Interventions in Urban Research Methods. Antipode. 48(5): 1337-1358

Phelan, J.E., Sanchez, D.T. and Broccoli, T.L., 2010. The danger in sexism: The links among fear of crime, benevolent sexism, and well-being. Sex Roles, 62(1-2), pp.35-47.

Philo, C. 2012. Security of geography/geography of security. Transactions of the Institute of British Geographers, 37: 1-7.

Roestone Collective. 2014. Safe Space: Towards a Reconceptualization. Antipode. 46:13461365 ,

Sparks, R.. 1992. Television and the drama of crime: Moral tales and the place of crime in public life: Open University Press Buckingham.

Stanko, E.A., 1990. Everyday violence: How women and men experience sexual and physical danger. Harper Collins.

Stanko, E.A. 1997. "Safety Talk: Conceptualizing Women's Risk Assessment as a Technology of the Soul'." Theoretical Criminology 1 (4):479-499.

The Independent. 2017. "The 11 safest countries in the world for expats." 2 February 2017.

The Strait Times Online. 2018. "Lee Hsien Loong relax laws on public protest for foreigners" 13 June 2018. http://statestimesreview.com/2018/06/13/lee-hsien-loong-relax-lawson-public-protest-for-foreigners/ Accessed 3/7/2018.

Valentine, G. 1989. "The Geography of Women's Fear." Area 21 (4):385-390.

van Bochove, M. \& Engbersen, G., 2015. Beyond Cosmopolitanism and Expat Bubbles: Challenging Dominant Representations of Knowledge Workers and Trailing Spouses. Population, Space and Place, 21(4), pp. 295-309.

Wilson-Doenges, G. 2000. "An exploration of sense of community and fear of crime in gated communities." Environment and Behavior 32 (5):597-611.

Yeoh, B.S.A. \& Willis, K., 2005. Singaporean and British transmigrants in China and the cultural politics of 'contact zones'. Journal of Ethnic and Migration Studies, 31(2), pp. 369-285.

Young, J. 1987. The tasks facing a realist criminology. Crime, Law and Social Change 11 (4):337-356. 